QUADERNS DE FILOSOFIA VOL. VII NÚM. 2 (2020): 59-8 I

eISSN: 234I-3042 DOI: I0.7203/QFIA. 7.2.I 8798

AnNA BUgaJsKa

Universidad Jesuita Ignatianum, Cracovia

\title{
Biopolítica y distopía: la genómica en Next de Michael Crichton
}

\author{
Biopolitics and dystopia: genomics in Michael Crichton's Next
}

Recibido: 6/10/2020. Aceptado: 18/12/2020

Resumen: En este artículo se busca demostrar que, mientras el desarrollo científico es propulsado por el pensamiento tecno-optimista (utópico), el discurso prevalente sobre genómica en la cultura de masas es pesimista (distópico) y tiene potencial para impedir la construcción de respuestas adecuadas a los desafíos biopolíticos por parte de los sistemas políticos y jurídicos. Aquí se sostiene que la utopía genómica es la única propuesta optimista que estimula las investigaciones científicas y que permite pensar en las posibles regulaciones y los cambios necesarios para la conceptualización de la idea de propiedad. Estos problemas son ilustrados con la ayuda del libro de Michael Crichton, Next, que proporciona numerosos ejemplos distópicos.

Summary: The article seeks to demonstrate that while scientific development is propelled by technooptimistic thought (utopian), the prevalent discourse about genomics is pessimistic (dystopian), which has the potential to forestall the construction of an adequate answer on the part of political and legal systems. It is shown that genomic utopia is the only optimistic proposition which stimulates scientific research as well as enables thinking about regulations and the necessary changes in the conceptualization of the idea of property. These problems are illustrated with the help of Michael Crichton's book Next, which provides numerous dystopian examples.

Palabras clave: biopolítica, distopía, genómica, sociedad abierta, autopropiedad, Crichton.

Keywords: biopolitics, dystopia, genomics, open society, self-ownership, Crichton.

*Agradezco a Lucas E. Misseri, Santiago Truccone Borgogno, Felipe Schwember Auger, y a los editores y evaluadores de la revista por su lectura de este texto y sus valiosos comentarios. 
If we have a right to live and be free, but our bodies are not free, then the other rights become irrelevant. ${ }^{1}$

People can't be owned. ${ }^{2}$

The genetic revolution is over, as far as law is concerned, because it cannot be regulated. ${ }^{3}$

\section{INTRODUCCIÓN}

\section{$\mathrm{E}$}

N EL AÑo 2000 el Proyecto Genoma Humano se concluyó con éxito: el genoma humano estaba descifrado. Sin embargo, la esperanza de la utopía genética, según la cual podríamos curar todas las enfermedades y mejorar la vida de los individuos y las sociedades gracias a la ingeniería genética, no se ha cumplido. El genoma humano nos ha dejado con más preguntas y problemas que antes. Hemos encontrado una tabla con "jeroglíficos" cuyo significado se nos escapa. Ahora bien, eso no quiere decir que nuestra esperanza se haya visto totalmente frustrada. En lugar de la utopía genética, vinculada a la investigación del ADN en su conjunto, nuestro sueño es la utopía genómica o — como dicen algunos observadores ${ }^{4}$ - postgenómica, vinculada al manejo de datos genéticos particulares en relación a los big data. Este cambio resulta de la combinación del desarrollo de la medicina genética, la telemedicina, la sociedad abierta y la biopolítica basada en los big data y el acceso libre.

"Genética" puede ser entendida en su sentido amplio, como la investigación de todos los genes del individuo (p. ej. la secuenciación del genoma), o, más específicamente, como la administración de datos genéticos. ${ }^{5}$ En este artículo prevalece el segundo sentido, clave para diferenciar la genética y la genómica. La genética se refiere al estudio de genes individuales y tiene una asociación fuerte con la eugenesia del siglo xx. La genómica, al contrario, es una concepción supuestamente liberada de asociaciones negativas. De hecho, se puede entender como antirracista y democrática, porque demuestra que las diferencias biológicas fundamentales entre las personas son minúsculas. Asimismo, es profundamente

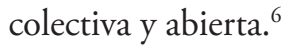

${ }^{1}$ SAndberg $2013,57$.

${ }^{2}$ Crichton 2005, 281.

${ }^{3}$ Morgan 200I, 186.

${ }^{4}$ Nelkin, Lindee 2004; Reardon 2017; Dewey-Hagborg 2017; Mukherjee 2017.

${ }^{5}$ Weidenslaufer et al. 2019; Reardon 2017.

${ }^{6}$ El uso de estas palabras en este contexto es típico de la narración utópica desplegada alrededor de la genética. Reardon $(2017,46-69)$ relata que la investigación genética ha traído esperanzas de una sociedad más justa e igualitaria, sin distinción de razas. 
Como leemos en "Ética de las investigaciones en genética humana", ${ }^{7}$ hay tres usos principales de los big data en genómica: el uso forense para la investigación de las personas; el uso médico, para identificar y combatir las enfermedades; y el uso farmacéutico, para desarrollar tratamientos personalizados. El problema ético que se presenta aquí es que sin los big data y la consiguiente cesión de una parte de la privacidad, no tiene mucho sentido secuenciar el genoma individual, pues sin ellos no se puede comparar la información genética de un individuo con la de otros. Aunque la genómica basada en la mediana estadística está cargada de errores, podría proporcionar a la sociedad notables ventajas. En relación a la medicina genómica, sobre todo a la medicina personalizada, Johnson et al. (2020) proponen principios éticos que regulen la esfera legislativa en el ámbito biopolítico de la genómica. Específicamente, han abordado el problema de la justicia (fairness). El individuo puede secuenciar su información genética y obtener tratamiento para sus propias enfermedades, así como calcular los riesgos para su familia y él mismo. Pero esta individualización de la medicina comporta pagar el precio recién indicado: para acceder al tratamiento personalizado, la gente debe entregar parte de su libertad y privacidad, hacer pública su información genómica. Por más que sea información vulnerable, no es posible asegurar que esta no vaya a ser utilizada por terceros, tales como las compañías genómicas, empresas, gobiernos $\mathrm{u}$ otros estamentos interesados en mercantilizar dichos datos. Es evidente que la falta de regulación y la falta de respuesta a los desafíos creados por los big data corre el riesgo de llevarnos a un futuro distópico. Morgan advirtió en 2001 que la revolución genética es incontrolable debido a su complejidad. Entonces, ¿la solución radica en dejar a la genómica sin control? ¿Qué tipo de biopolítica debemos seguir? ¿Cómo proteger a la gente contra el abuso de datos sensibles?

Los problemas señalados no son los únicos que afectan al mundo postgenómico y su biopolítica. La desigualdad social, los organismos transgénicos, la human enhancement y el sacrificio de la autopropiedad son otros igualmente relevantes y espinosos. Tanto que la respuesta habitual de la imaginación colectiva ante los desafíos de la genómica suele ser la distopía. ${ }^{8}$ En el presente artículo examinaré los problemas de propiedad y privacidad en la biopolítica tomando como objeto de estudio la novela Next (2005), de Michael Crichton. El conocido escritor de ciencia-ficción, llamado el Verne contemporáneo, ${ }^{9}$ abordó hace ya quince ańos algunas de las cuestiones relativas a la sociedad postgenómica que estamos tratando de manejar ahora. ${ }^{10} \mathrm{~A}$ lo largo de las páginas sucesivas, defen-

${ }^{7}$ Penchaszadeh 20i8a, 33.

${ }^{8}$ Clayton y Wald 2007; Mukherjee 2017.

${ }^{9}$ michaelcrichton.com (BERNSTEIN I997).

${ }^{10}$ Puede ser discutible si podemos llamar al libro de Crichton una distopía. Claeys (2017) sostiene que el género de la distopía se acabó con la Segunda Guerra Mundial. Sin embargo, he mostrado (2019) que las distopías contemporáneas son distintas de las del pasado y que muchas 
deré la siguiente tesis: aunque las ideas de data sharing, así como las de propiedad individual o corporativa, pueden dar lugar a soluciones distópicas, como sucede en Next, es necesario formular respuestas utópicas capaces de construir una biopolítica estable y viable que sirva de alternativa al fatalismo y a la peligrosa desregulación imperante. Más específicamente, analizaré las amenazas que suscitan la retirada del Estado de la esfera de la biopolítica, la comercialización de los big data y la pérdida de privacidad del cuerpo humano.

\section{LA BIOPOLÍTICA Y LA DISTOPÍA}

La biopolítica ${ }^{11}$ es un elemento esencial en la construcción de la distopía desde su inicio, ya sea en su preocupación por la salud humana o el medio ambiente. De hecho, si la biopolítica es la política dirigida al manejo del bios, resulta que todos los libros distópicos incluyen detalles sobre el poder de la vida y muerte de los ciudadanos por parte del Estado. Al inicio, sin embargo, necesitamos preguntarnos: ¿̨cuál es el Estado distópico?; ¿qué es la distopía biopolítica?; ¿podemos hablar de biopolítica distópica? Las respuestas a semejantes preguntas se pueden buscar tanto en casos reales como en la ficción distópica.

En cuanto a lo primero, por Estado distópico se entiende usualmente al Estado totalitario, centralizado y omnisciente. Cuando pensamos en la biopolítica de la regulación de la reproducción en China, el control del sexo en las novelas de Zamiatin y Swift o los experimentos nazis en los campos de concentración, el carácter distópico de estas prácticas no plantea dudas. No obstante, la distopía puede fomentarse también en los estados democráticos, sedes de la economía descentralizada y la propiedad privada. Ahí están la desigualdad económica y social, la falta de atención a los grupos desfavorecidos, la precariedad sistémica y el racismo para corroborarlo. En la ficción distópica más reciente, se enfatiza con frecuencia el poder de las corporaciones, la mercantilización de la vida humana y el impacto nocivo del capitalismo sobre el medio ambiente. La chica mecánica (2009), de Paolo Bacigalupi, inspecciona los problemas de la modificación genética relacionados con el abuso de los seres posthumanos. En iHagan sitio! ;Hagan sitio! (1966), de Harry Harrison, la preocupación recae sobre la sobrepoblación.

de ellas, sobre todo las que tratan de la biotecnología, se fusionan con los thrillers. Muchos otros teóricos, como Schmeink (2016), también se hacen eco de esta hibridación de géneros y aluden a cierta imaginación distópica sin llamar a un libro distopía genérica.

${ }^{11}$ La biopolítica designa el manejo de los cuerpos por parte del Estado. Los aspectos que más nos interesan aquí son la salud humana y sus relaciones bioeconómicas. Aunque la discusión se apoya sobre las relaciones de poder y las concepciones de la vida y la muerte, disputadas entre otros por Foucault, Agamben y Esposito, el contexto más inmediato de mi trabajo son las ideas de Thomas Lemke, Byung-Chul Han, Bruno Latour, Nikolas Rose y Catherine Waldby. 
El atlas de las nubes (2005), de David Mitchell, reproduce la visión huxleyana de una sociedad constantemente medicada a fin de evitar el pensamiento libre. Obras así, advierten que la biopolítica puede desembocar en una distopía, aviso que también emiten las ficciones postapocalípticas o apocalípticas de Stephen King (La danza de la muerte, 1978) o Dan Wells (Parciales, 20 I 2-20I4).

Desde luego, resultaría excesivo catalogar de distopía biopolítica a todos los casos. A mi modo de ver, paso a los otros interrogantes, la distopía biopolítica designa a una organización del Estado que produce efectos indeseables durante el desarrollo biotecnológico llevado a cabo sin regulación ni reflexión. Los resultados distópicos de semejante biopolítica se pueden denunciar desde numerosos enfoques, sea el principio de responsabilidad de Hans Jonas o la teoría de las capacidades de Sen y Nussbaum. ${ }^{12}$ Lemke (2013) defiende que algunas formas de distopía relativas a la genética ya se están produciendo. Otros teóricos informan que en lugar de la utopía genética, ${ }^{13}$ con sus promesas de un mundo de salud y perfección, ${ }^{14}$ ha llegado una distopía genética, mientras que el sueño biopolítico muta en utopía genómica. ${ }^{15}$

La ficción lleva mucho tiempo alertando sobre esas posibilidades. La isla del doctor Moreau (I 896) es un ejemplo temprano de la discusión sobre las criaturas transgénicas, que H. G. Wells liga la vivisección. Su visión horrorosa e inquietante descansa sobre la herencia del gótico anglosajón y pinta a los posthumanos genéticos como monstruos, controlados solo por la Ley. Aunque el protagonista, Edward Prendick, con el tiempo se acostumbra a los hombres-bestia, finalmente son ellos quienes pierden su humanidad y vuelven a comportarse como animales, lo que hace que la convivencia sea muy peligrosa, incluso imposible. Más de un siglo después de Wells, la trilogía Oryx y Crake (2003-2013) de Margaret Atwood culpa al consumismo de Occidente y a las corporaciones que abusan de la naturaleza en pos de las ganancias. La escritora canadiense también aborda el tema de los seres transgénicos, aunque no humanizados, pero muestra una raza de posthumanos pacíficos, llamados "crakers", que viven en su propia comunidad, sin instituciones ni mercado. Esta realización contemporánea del tema del buen salvaje sugiere que el futuro postgenómico podría traer cambios deseables, siempre que el capitalismo desenfrenado se desmantelara. En textos un poco anteriores, los que forman la Saga de los Insomnes (I99I-1996), Nancy Kress habla de la desigualdad genética que intensifica, más si cabe, las desigualdades ya existentes. Esta trilogía de ciencia-ficción presenta muchos de los problemas que se discuten hoy: sobre todo, en torno a la justicia genética y al acceso al mejoramiento hu-

\footnotetext{
${ }^{12}$ Jonas i 985 ; Sen i992; Nussbaum 20 i I.

${ }^{13}$ Nelkin, LindeE 2004.

${ }^{14}$ VAN Est y STEMERLing 2012.

${ }^{15}$ REARDON 2017.
} 
mano. Algunos padres, para dar ventaja a sus hijos, los someten a modificaciones genéticas, decisión que tiene éxito pero con el coste añadido de llevar a las personas mejoradas a vivir encerradas en su propia microtopía, profundizando las brechas sociales según el nivel de mejoramiento. Este tipo de reflexión se desarrolla ahora, mayormente, a partir de la producción cinematográfica. Podemos mencionar Gattaca (1997), que sigue siendo paradigmática por conjugar el discurso contrario al determinismo genético y enfocar la división social según el ADN; o Blade Runner (1982), donde se esclaviza a los replicantes - humanos artificiales-. Recientemente, prospera una visión más utópica en las películas de Marvel (p.ej. Avengers: Endgame, 2019), o en series como Héroes (NBC, 2006-2010), productos que retratan a la gente modificada o genéticamente superior como superhéroes. Sin embargo, la perspectiva distópica es todavía muy prominente, como confirma Biohackers (Netflix, 2020), serie reciente. La trama principal de estas producciones es la lucha por el biopoder en un mundo postgenómico.

No cabe duda de que el discurso distópico sobre la genética tiene gran protagonismo en la cultura popular. Este planteamiento penetra en la retórica de los bioéticos y los empresarios del ámbito genómico, ${ }^{16} \mathrm{e}$ impacta en lo que Loven y Pavone (2015) llaman la "bioeconomía", "acto de imaginación" ${ }^{17}$ rodeado de dos escenarios distópicos potenciales. En el primero, la bioeconomía global no se desarrolla y no existen regulaciones que controlen la biotecnología. En el segundo, las naciones protagonizan una guerra fría o una especie de "carrera espacial" por el control de la bioeconomía global. ${ }^{18}$ Florencia Devy se pregunta: "¿Qué pasa si viene una compañía de Estados Unidos para secuenciar el ADN de los chilenos y vender remedios para Chile? No hay ninguna norma. Nuestro patrimonio genético es nuestro y debemos protegerlo". ${ }^{19}$ Como Canguilhem (1978) anticipó: "En

${ }^{16}$ Byers y Stapleton 20 I 5; Hyde y Herrick 20i3; Tutton 201 i.

${ }^{17}$ Loven y Pavone $2015,304$.

${ }^{18}$ Loven y Pavone 201 5, 314. La traducción es mía.

${ }^{19}$ Fajardo 20i 8 . Esta cuestión aún se debate. Se reconoce al genoma humano como patrimonio común de la humanidad en la Declaración Internacional sobre el Genoma Humano y los Derechos Humanos de la UNESCO (1997), texto apoyado sobre los ideales de la naturaleza humana, caso de la dignidad, la diversidad y la unidad de la especie. Su significación no es únicamente biológica, sino simbólica. En su momento, el concepto de patrimonio común en el derecho internacional se aplicaba a recursos o territorios como el espacio exterior o el fondo del mar. Pero se ha argumentado que en lugar de "patrimonio", deberíamos hablar de "recurso común" (RESNIK 2005). Entonces, podemos preguntarnos si el genoma humano es una propiedad común o una responsabilidad común. En el primer caso, enfatizamos los problemas de los beneficios y de la justicia distributiva. En el segundo, el sentido normativo y la protección del genoma (PRIMC 2020). En cuanto a las estrategias nacionales, Islandia permitió a sus ciudadanos el acceso a los datos genéticos, pero Japón protegió los datos de los suyos (REARdon 2017, 70-93, 94-119). Sin embargo, la biopolítica nacional no está regulada solamente por conceptos, sino también por las condiciones económicas. Los países que no disponen de la tecnología para el manejo de la información genómica, necesitan subcontratar los servicios genómicos, y en consecuencia, permitir el acceso a los datos privados a terceros, lo cual pone en riesgo la seguridad nacional. 
el inicio de este sueño tenemos una ambición generosa: que vamos a ahorrarle a los seres vivos inocentes e impotentes la carga atroz de producir errores de la vida. Al final está la policía genética, vestida con la ciencia de los genetistas" ${ }^{20}$ Afirmaciones así, potencian la percepción de que el escenario distópico es más probable que el utópico.

Reardon habla del principio de apertura de las islas Bermudas (the Bermuda principle of openness ${ }^{21}$ ) para criticar las visiones utópicas de los afines a la genómica. Se trata de una sociedad abierta, con data sharing y Personal Genome Project, donde la privacidad se halla sujeta al bien común, regulada solamente por la buena voluntad de los participantes. La sociedad abierta se caracteriza por la transparencia total y la confianza mutua. Data sharing designa a la práctica académica de proporcionar acceso a los datos utilizados para la publicación, o, más ampliamente, a la práctica cotidiana de compartir los datos en las redes sociales. Personal Genome Project parte de estos conceptos de confianza y transparencia a fin de recabar y estudiar los datos genéticos de voluntarios que permitan la genética y la medicina personalizada. Reardon advierte de las falacias inherentes al "cuento de hadas" de las islas Bermudas: "Las Bermudas son islas. Una tierra de sueños e ideales donde uno puede caminar circulando el Lago de Amante y surfear en el agua de azul cristalino y nadar con los delfines. Mientras que Bermudas sigue viviendo como el mito fundacional clave de la genómica abierta, responsable e ilustrada, la vida fuera de las islas ha demostrado que la historia nunca ha sido tan sencilla". ${ }^{22}$

Dentro de este mismo ambiente, Crichton presenta en Next una distopía en la que el supuesto paraíso del data sharing es corrompido por universidades, centros de investigación y corporaciones. La falta de regulaciones, la ignorancia de pacientes y jueces, solo es superada por la ignorancia y la ligereza de las prácticas de la genética. Sin embargo, Crichton, un conocido tecnófilo, no busca apoyar a los bioconservadores extremos. Más bien, intenta mostrar algunas fallas en el funcionamiento de la sociedad actual con la voluntad de evitar las amenazas que relata. A lo largo de la sección siguiente, reflexionaré sobre los puntos débiles de la posible biopolítica genómica a partir de la novela del escritor estadounidense.

\section{La Distopía genómica en NEXT}

El libro de Crichton es muy difícil de resumir, por su polifonía narrativa y su construcción, que mezcla lo real y lo ficticio en una manera parecida a la

\footnotetext{
${ }^{20}$ LeMKe 2013, 2. La traducción es mía.

${ }^{21}$ REARDON 2017, 34.

${ }^{22}$ Reardon 2017, 34. La traducción es mía.
} 
de los clásicos de la utopía. Como Moro o Swift, Crichton añade un paratexto amplio para ayudar a la verosimilitud del relato. En la dedicatoria, el autor subraya que lo que sigue es una ficción "con excepción de las partes que no lo son" y el libro concluye con el ensayo This Essay Breaks the Law, donde explica su punto de vista sobre el manejo de la información genética y los tejidos. En el final de Next tenemos otros materiales (p. ej. Author's Notes) que proponen un plan de mejoramiento de la biopolítica, así como una bibliografía amplia con muchos comentarios. La versión electrónica incorpora también videos y entrevistas con el escritor acerca del tema.

Durante los párrafos sucesivos enfocaré los pasajes de la trama más relevantes para mi artículo. Sin embargo, antes de todo, sería útil mostrar que parte de la crítica formulada por Crichton del mundo postgenómico depende del aparente desorden narrativo con el que pretende reflejar la compleja realidad, apuesta que sirve como herramienta literaria con la que satirizar los males de la biodistopía neoliberal. Podemos contar al menos ochos tramas, salpicadas de recortes de periódicos y noticias que muestran el caos informativo del periodismo de la posverdad. Los primeros actores de la escena biopolítica son: BioGen, la corporación biotecnológica, representada como una entidad colectiva; Frank Burnet, el paciente, y su familia; dos investigadores, Henry Kendall y Gail Bond, que logran crear seres transgénicos al margen de las compañías; y los animales transgénicos: Dave y Gerard. En relación con BioGen, hay algunos empleados que tienen sus propias subtramas, como Josh Winkler, un investigador, o Vasco, un cazarrecompensas.

La trama principal de Next se construye alrededor del problema de las patentes genéticas, que en el tiempo de publicación de la obra centraron el debate legal dentro del ámbito biotécnico, pero también alude a las reglas de manejo de tejidos, implicadas en la cuestión de la propiedad genómica, y a las líneas celulares, estudiadas por sus usos genómicos. A partir de estos mimbres, Crichton narra las peripecias de Frank Burnet, paciente que recibe en Los Angeles Medical Center el tratamiento para leucemia linfoblástica aguda de células $\mathrm{T}$. El centro toma muestras de tejidos y descubre que su línea celular es extremadamente valiosa porque produce citoquinas especiales, proteínas que participan en los procesos inmunológicos. Burnet se entera que el centro ha vendido los derechos de su línea celular a BioGen, y presenta una demanda legal. Dice que

Había ido al Dr. Gross cuando estaba enfermo, asustado y vulnerable. Había confiado en mi médico. Había puesto mi vida en sus manos. Yo confiaba en él. Y luego resultó que me había estado mintiendo y asustándome innecesariamente durante ańos, solo para poder robar partes de mi propio cuerpo y venderlas 
para obtener ganancias. Para él mismo. Nunca se preocupó por mí en absoluto. Solo quería llevarse mis células ${ }^{23}$

El caso es que el paciente no tiene derecho a sus células porque han sido removidas de su cuerpo. Los abogados de BioGen postulan que incluso si las células de Burnet son declaradas propiedad privada por la Corte Suprema, el gobierno, y por ende la universidad estatal, se encuentra legitimado para obtenerlas bajo el principio de expropiación. ${ }^{24}$

Aunque Jones (2008) critique a Crichton por el sensacionalismo del caso, es evidente que la tensión entre la propiedad privada y la pública es uno de los problemas no resueltos de la genómica. La misma visión utópica que promete la medicina personalizada - la libertad morfológica y la consumación de los sueños individuales_- amenaza a la autopropiedad, símbolo y fundamento de su filosofía. La autopropiedad, insisten los adeptos, debe ser restringida en beneficio del progreso científico y el bienestar común. La misma retórica bélica que alienta a donar sangre en solidaridad con los compatriotas es utilizada ahora para argumentar el deber de donar nuestros datos genéticos. ${ }^{25} \mathrm{El}$ mensaje implícito es que no construiremos una sociedad más sana mediante la medicina personalizada si nos negamos a ingresar en el "mundo feliz" de los big medical data. Irónicamente, en el mundo distópico de Crichton las compañías como BioGen no se preocupan por la calidad de la utopía que prometen realizar. Bellarmino, jefe de Henry Kendall, divulga la idea de un futuro esplendoroso para la medicina, pero al mismo tiempo promociona su propia agenda hablando con los miembros del Congreso:

La idea de sufrir los inquietaba. También la idea de permitir que los lisiados volvieran a caminar. Por supuesto, nadie sabía si eso sucedería alguna vez. Personalmente, Bellarmino dudaba de que fuera a suceder. Pero déjenlos que piensen que va a pasar. Déjenlos que se preocupen. Deberían hacerlo: había mucho en juego y el ritmo de avance era rápido como un cohete. Cualquier investigación que Washington bloqueara tendría lugar en Shanghai, Seúl o São Paulo. Y Bellarmino, hábil y mojigato, pretendía asegurarse de que nada parecido ocurriera nunca. Nada que pudiera interferir con su laboratorio, su investigación y su reputación. Era muy bueno protegiendo a los tres ${ }^{26}$

Más problemas saltan a la vista. Por su carácter íntimo, la información genética debe evaluarse como contenedor de datos sensibles, no solamente por-

${ }^{23}$ Crichton 2005, 23. La traducción es mía.

${ }^{24}$ Normalmente se trata de bienes inmuebles que pueden ser apropiados por el gobierno, pero en el caso Burnet, los abogados invocan esta misma regla en relación al genoma.

25 Waldby y Mitchell 2006; Reardon 2017.

${ }^{26}$ Crichton 2005, 121. La traducción es mía. 
que atañen a la identidad personal, sino porque su revelación es susceptible de poner en peligro o comprometer a otros, caso de familiares. La autopropiedad desborda la propiedad privada en la medida en que otras personas también pertenecen a nuestro ADN. Crichton relata cómo la familia de Burnet sufre amenazas de BioGen, ya que supuestamente posee información que no es suya. Gracias a la cesión de sus tejidos, Burnet recibe, en efecto, un tratamiento que funciona, pero a cambio de perder los derechos de su línea celular y poner en riesgo a sus familiares. Crichton enseña que las repercusiones morales y legales de la medicina personalizada trasciende al donante de los tejidos e implican a todos aquellos con quien este se halla biológicamente relacionado. Su consentimiento informado y consciente no debe entrañar la cesión de los derechos a la línea celular que comparte con otros. En caso contrario, así ocurre en Next, la compañía biotecnológica de turno se sentiría legitimada para reclamar la propiedad de las células de personas ajenas al proceso.

Los hándicaps de la farmacogenética también emergen en la trama de Adam Winkler, adicto a las drogas que toma accidentalmente la medicación experimental del "gen de la madurez" y se convierte en un ciudadano responsable y amable, éxito que anima a los científicos a proceder con experimentos humanos no autorizados. Sin embargo, la "madurez" trae aparejada la intensificación del proceso de envejecimiento y la muerte prematura. Crichton aborda la irresponsabilidad de los científicos con un escepticismo similar al de Oreskes (20I I; 2019) o Woolgar y Latour ( 1985 ). "La ciencia es una actividad humana tan corruptible como cualquier otra. Sus practicantes no son santos, son seres humanos y hacen lo típico de los seres humanos - mentir, engañar, robar, demandar, ocultar datos, falsificar datos, sobrevalorar su propia importancia, así como denigrar injustamente las opiniones opuestas. Es la naturaleza humana. No va a cambiar". ${ }^{27}$

Crichton examina, además, el problema de los seres transgénicos, disputados por los bioeticistas y desarrollados, entre otros, por científicos españoles y japoneses. En particular, podemos mencionar dos. Gerard, loro inyectado con genes humanos. Puede pensar y hablar, y deviene en tutor del hijo del investigador de biotecnología. Luego, será transferido de un propietario a otro, hasta que finalmente escapa. Para los objetivos de este artículo, destaca especialmente el personaje de Dave, un "humancé", chimpancé con genes humanos creado por Henry Kendall como parte de un experimento no autorizado. Habla y participa en la vida social humana de forma limitada. Una pregunta que enfrenta Kendall es: ¿̨i un humancé tiene información genética de humano en su cuerpo, debería ser considerado familiar del donante? El científico, supuesto "padre" de Dave, confronta su responsabilidad y lleva al humancé a su casa,

${ }^{27}$ Crichton 2005, 62. La traducción es mía. 
suponiendo que es un hijo suyo que padece una enfermedad imaginaria. Sin embargo, los demás pronto se dan cuenta de la verdad: "La familia más moderna ya no es una familia del mismo sexo, ni una familia mixta, ni una familia interracial. Todo eso está tan fuera de moda, dice Tracy Kendall. Y debe saberlo, porque la familia Kendall de La Jolla, California, es transgénica e interespecie, lo que genera más emoción en el hogar que un barril de monos!". ${ }^{28}$ Aunque la socialización familiar funciona, Dave sufre bullying en la escuela y se mete en peleas. Como concluye Crichton, "la gente no estaba preparada. Los liberales eran liberales solo hasta cierto punto". ${ }^{29}$ Claramente, desde el punto de vista de los seres transgénicos, el mundo postgenómico sigue siendo una distopía.

Crichton desvela, igualmente, la comercialización de lo genómico a través de los intereses mostrados por los empresarios en la modificación genética de seres vivos. Los anuncios genómicos, promocionados como filantropía e inscritos en la RSC (la responsabilidad social corporativa), muestran los esfuerzos de la genómica corporativa por apelar a la retórica de la utopía. Next relata el caso de una adolescente que vende sus óvulos. Los senadores sienten que ni han sido conscientes de lo que ha estado pasando ni tienen medios con los que enfrentar la autopropiedad. "¿Cuál sería la base para prohibirlo? [...] Sus cuerpos, sus óvulos," dice la Senadora Spencer. ${ }^{30}$ Los abogados representantes del mundo biotecnológico, responden: "Si soy dueño de una fórmula para hacer algo, y alguien hace una copia de esta fórmula en una hoja de papel y se la da a otro, ella sigue siendo mi propiedad. Soy dueño de la fórmula, no importa cómo sea copiada o para quién. Y tengo derecho a recuperar esa copia". ${ }^{31}$

Este dilema se puede complejizar cuestionando la concepción de autopropiedad. Morgan (200I), en Issues in Medical Law and Ethics, recalca que este tipo de propiedad, el derecho al propio cuerpo, es básicamente un derecho negativo, en el sentido de que los demás no pueden reclamar la propiedad del cuerpo de otro. Él lo llama el sentido estrecho (limited sense) de la propiedad: mi cuerpo no es tuyo. De esto no se sigue que mi cuerpo es mío en sentido metafísico o que es propiedad ajena (como p. ej. una casa): "En el sentido más profundo, mi cuerpo no pertenece a nadie, ni siquiera es mío". En realidad, lo que Crichton está satirizando es el proyecto de patentar los genes, cuestión candente en el tiempo de la publicación de la novela y que ahora ocupa un lugar secundario al haberse reconocido que los genes son hechos naturales: al igual que el oro, no se pueden patentar y funcionar como la propiedad industrial, y al igual que la luz del sol, no se pueden vender o comprar. Sin embargo, si asu-

\footnotetext{
${ }^{28}$ Crichton 2005, 412. La traducción es mía.

${ }^{29}$ Crichton 2005, 301. La traducción es mía.

${ }^{30}$ Crichton 2005, 361. La traducción es mía.

${ }^{31}$ Crichton 2005, 375. La traducción es mía.
} 
mimos que nuestros cuerpos son hechos naturales, sin un propietario, ¿cómo manejarlos?; ¿cómo construir una biopolítica?; ¿¿de quién es la responsabilidad?

Crichton enfatiza la impotencia de la biopolítica frente a los hechos científicos y la práctica comercial. Una de las razones es, el ejemplo de los óvulos lo ilustra, la falta de formación adecuada. Como dicta el Informe de la ponencia de estudio sobre genómica del Senado de las Cortes sobre la medicina genómica y personalizada, ${ }^{32}$ "la interpretación de los datos ha de basarse en el conocimiento de la biología de la enfermedad, en la clínica del paciente y en los datos genómicos epidemiológicos". Lamentablemente, muchos actores de la escena biotecnológica, no solo los políticos, carecen de tal conocimiento. Tutton (20I I) afirma que lo único que ofrecen las compañías de la genómica personal es incertidumbre. Reardon advierte que las citadas compañías de la genómica personal no consideran la ausencia de conocimiento apropiado un problema:

Desde luego, las declaraciones como esta de un científico personal de una compañía de la genómica personal han provocado inquietud: "Yo no sé nada de la enfermedad $[\mathrm{X}]$, pero... en general nuestra filosofía es recoger muchos datos y tratar de darles voz, y entender qué tipo de historias ocultan." Para este científico, la falta de conocimiento previo de la enfermedad $[\mathrm{X}]$ no es un problema, sino una ventaja a celebrar: "Viajo para exponer ante unos biológicos y les digo: 'Sí, no sé nada de biología. Estoy orgulloso de esto. Me hace trabajar mejor”’33

\section{Cómo eVITAR la distopía en la biopolítica de La ERA (POST)GENÓMICA}

Mi tesis es que la narración pesimista no ayuda a combatir los problemas de la recién nacida genómica; tampoco la ligereza del optimismo ingenuo. El objetivo de la presente sección será sopesar posibles alternativas que eviten la distopía genómica y articulen un utopismo alternativo, no solo de dicha distopía, sino también de la utopía neoliberal. Ésta última promete un paraíso sin reglas en el cual la libertad individual desbordada se junta con la inmortalidad, la perfección corporal y las terapias milagrosas. ${ }^{34}$

Crichton critica la utopía del mercado genómico libre, la utopía neoliberal y la utopía tecno-optimista. En todos los casos, nos invita a pensar: ¡cuál debería ser la decisión del juez? ¿Cuál la respuesta de los Senadores? ¿Qué

32 Informe de la ponencia... 2019, 15.

${ }^{33}$ REARDON 2017, 142. La traducción es mía.

${ }^{34}$ Véase también la propuesta de Goven y Pavone de la utopía bioeconómica en "The Bioeconomy as a Political Project: A Polanyian Analysis" (2015). 
implica el problema de las patentes para la sociedad abierta? El autor no ofrece conclusiones claras, a pesar de la amplia bibliografía disponible. ${ }^{35}$ No obstante, se puede inferir su posición explorando el modo en que presenta los casos y atendiendo a sus comentarios en el paratexto. Crichton apoya la transparencia de los experimentos genéticos y de los datos pertenecientes a las compañías y universidades que llevan a cabo las investigaciones. Al mismo tiempo, desaconseja las limitaciones gubernamentales de la investigación y respalda la privacidad de los pacientes, así como su autopropiedad, alegando la necesidad de aprobar leyes sancionadoras relativas al manejo de los tejidos que impidan los absurdos imaginados en su novela. Señala que "nuestros cuerpos son nuestra propiedad privada. En el sentido de que la autopropiedad es el tipo de propiedad más fundamental conocida. Es la experiencia esencial de nuestro ser" ${ }^{36}$ Pero Crichton no intenta resolver el problema de los genes entendidos a modo de hechos naturales que no pertenecen a nadie, ${ }^{37}$ en contraste con el genoma de la única persona y su propiedad. Lo único que comenta es que incluso si no tenemos autopropiedad en sentido absoluto, eso no significa que seamos "minas de oro que podrían ser saqueadas a voluntad, una y otra vez" por las compañías biotecnológicas. ${ }^{38}$

$\mathrm{Al}$ ser consultado en una entrevista acerca de las reglas para combatir la "ciencia mala" y evitar la distopía genómica, el escritor respondió:

Creo que en realidad hay tres o cuatro cosas que realmente transformarían el campo. Lo primero que haría sería legalizar completamente las pruebas de genes para diagnósticos médicos, independientemente de las patentes. [...] Lo segundo que haría es exigir a las universidades que sigan las directrices federales para el uso de tejidos en la investigación. [...] La tercera cosa que haría es asegurarme de que las personas obtengan la información que necesitan para tomar decisiones informadas. Ahora hay algunas situaciones en las que los pacientes han muerto a causa de la terapia génica, y las instituciones involucradas han dicho que no quieren que se informe sobre las muertes porque son un secreto comercial. [...] Y lo último es que en 1980 se aprobó una ley que se llamó BiDole, ley bipartidista que permitía a las universidades vender sus productos a la industria, y fue bien intencionada, pero ha tenido el efecto de crear esta gigantesca conglomerado comercial dentro universidades que es muy dańino, por lo que revertiría esa ley ${ }^{39}$

${ }^{35}$ Contreras 2008; Jones 2008.

${ }^{36}$ Crichton 2005, 394. La traducción es mía.

${ }^{37}$ CRichton 2005, 395.

${ }^{38}$ CRichton 2005, 376.

${ }^{39}$ Crichton 2005, 416. La traducción es mía. 
Algunas propuestas de Crichton son muy generales y controversiales. Con todo, el novelista tiene claro que necesitamos encontrar soluciones que gestionen el mercado y la práctica clínica. Al buscar la respuesta al reto regulatorio en la sociedad postgenómica, existen varios documentos en los que nos podemos apoyar. ${ }^{40} \mathrm{El}$ hecho estriba en decidir qué propuesta concreta de la biopolítica genómica es la mejor para evitar la formación de un sistema distópico. Por un lado, el modelo centralizado amenaza con favorecer rasgos propios de la distopía totalitaria. Por otro, el modelo descentralizado amenaza con derivar en la instauración de una distopía liberal. ${ }^{41}$ Los centros de conservación y análisis de los datos genómicos nacionales deberían proteger los intereses de las naciones, pero eso amenaza, a su vez, la genómica global y abre la puerta a biopolíticas nacionalistas. Los centros privados probablemente serán regulados por los poderes del mercado, llegando a la objetivización de la vida humana. Entonces, ¿cuál es el camino a seguir?

Hace escasos meses apareció una defensa de la utopía de la genómica personalizada en European Journal of Human Genetics (2020). Johnson et al. sostienen que, sobre el principio de justicia (fairness), los pacientes tienen la obligación ética de compartir sus datos: no solamente genéticos, sino en general todos los que pertenecen a la salud. Además, los autores señalan que el consentimiento informado es innecesario si se usa la información genómica con el único fin de desarrollar la ciencia médica. Desde luego, enumeran condiciones para garantizar que dicha información no sea explotada y prevalezca la seguridad de los datos. Las condiciones son las siguientes:

1. Se necesita asegurar que la información genómica no esté conectada con la información personal y que sea salvaguardada por una política estricta de protección de datos. El riesgo de la seguridad de los datos debe ser balanceado con los beneficios potenciales para los pacientes.

2. Se deben establecer regulaciones y principios de conducta en las áreas siguientes: los términos de acuerdo para el acceso a los datos; recopilación, almacenamiento y uso de datos; servicios genómicos públicos y privados.

\footnotetext{
${ }^{40}$ P. ej. Mathaiyan et al. (2013), Nuffield Council on Bioethics (2018), Weidenslaufer et al. (2019).

${ }^{41}$ Felipe Schwember Augier (2019) señala las facetas distópicas inmanentes a la utopía liberal del derecho privado. Dice que "La noción que de la voluntariedad y de los derechos subjetivos tienen los libertarios conduce por sí misma a ciertos resultados distópicos (como, por ejemplo, la admisión del chantaje como práctica legal) o desactiva principios y prohibiciones, frecuentes en los ordenamientos jurídicos, que precisamente evitan dichos resultados distópicos (por ejemplo, para evitar que las conductas discriminatorias puedan ser consideradas un derecho, etcétera)" (SCHWEMBER Augier 2019, 90). Si nos preguntamos para qué personas sería una distopía la genómica liberaldesregularizada, la respuesta es obvia: para los pacientes, convertidos en meros consumidores, para los consumidores de los servicios genómicos a quienes les falta el conocimiento para dar su consentimiento realmente informado y para los seres no humanos, sometidos a la esclavitud y explotación.
} 
3. Se debe reaccionar a la desigualdad con respecto al acceso a los beneficios de la medicina genómica y tenerlo en cuenta en la planificación.

4. Se necesita supervisar la actividad en el ámbito legal.

Las condiciones enumeradas y las definiciones básicas son bastante amplias. Por ejemplo, ¿qué significa el desarrollo de la ciencia médica?; ¿qué se entiende por "servicios genómicos"?; ¡cómo supervisar el ámbito legal? Además, los autores opinan que la práctica de la recolección de datos genéticos y su administración han de ser reguladas por la confianza pública. Una base tan inexacta demuestra que tratamos con una expresión ingenua del pensamiento utópico, con una visión ideal más que con una biopolítica alternativa capaz de incidir en la práctica. Lo problemático es que en el momento actual solo contamos con propuestas parecidas, repletas de riesgos, entre ellos los siguientes: ${ }^{42}$

1. La categoría de healthy $i l^{43}$ —asignada a personas con mutaciones genéticas no deseables - puede impactar en las carreras, seguridad y vida familiar de los individuos afectados y favorecer nuevas formas de discriminación y eugenesia.

2. La autonomía individual del consumidor o paciente podría ser violada por la falta de conocimiento del carácter de la medicina genómica, las posibilidades de protección de datos, así como por el uso futuro de los datos no conocido en el momento de la entrega de los mismos.

3. El abuso de los datos genómicos por terceras partes y proveedores de los servicios genómicos y la violación de los derechos de propiedad.

4. La responsabilidad personal puede ser extendida inapropiadamente.

$\mathrm{Al}$ abordar estos riesgos, se deben reconsiderar:

1. Las concepciones de salud y enfermedad, con el objeto de evitar la categorización de la gente como enfermos en el supuesto de que tengan mutaciones que no desemboquen necesariamente en una enfermedad.

2. La autonomía del ciudadano/paciente: ¿cómo se puede entender el consentimiento informado en la era postgenómica? ¿Qué significa el interés público? ¿En cuáles casos el interés público puede superar al interés privado?

${ }^{42}$ Véase p. ej. Morgan (200I, 183-4), para una lista más detallada. También, Victor Penchaszadeh (20I8A; 20 I8B) señala que la base de la protección de la seguridad del paciente es el consentimiento informado y el respeto por los derechos humanos. Lo que se necesita saber, antes de todo, es cuál sea el interés público y quién decide sobre ello. Para proteger la autonomía del paciente, debe desarrollarse una variedad de formas de procesamiento de los datos genómicos, y asegurar su disponibilidad. Lo peligroso es la tendencia a entender el interés público/colectivo como interés industrial/comercial.

${ }^{43}$ Morgan 200I. 
3. La cuestión de la propiedad: si mi cuerpo no pertenece a nadie, ¿tengo derecho a compartirlo? ¿Hay una comunidad global o comunidades étnicas basadas en similitudes del genoma? ¿Qué tipos de obligaciones éticas eso trae para la gente?

4. La responsabilidad personal: ¿somos responsables de quienes utilizan nuestro genoma?

5. El concepto de información: es necesario darse cuenta que el apoyo al data sharing no significa lo mismo en contextos diferentes. La información de biología molecular no se puede ecualizar con la misma información en la teoría de la comunicación (p. ej. como sujeta a los mismos procesos de ficción y metaforización), sino que tiene un carácter distinto. ${ }^{44}$

Queda claro que la tensión entre la visión utópica del data sharing y los derechos basados en la propiedad privada y la autopropiedad constituyen el núcleo del problema. El consentimiento informado enfrenta retos como la falta de educación y las conclusiones de la ciencia genómica, que señalan que las personas forman una familia global, y que no disfrutarán de los beneficios de la medicina personalizada si no someten sus datos a los biobancos y rechazan integrar la comunidad nacional o global. La visión de Johnson et al. (2020) parece arriesgada, pero la regulación estricta tampoco ayuda a resolver los problemas de la sociedad postgenómica. Seguramente, el desafío consista en diseñar un sistema legal que evite, al mismo tiempo, la vulneración de la privacidad individual típica de las distopías totalitarias. Teniendo en cuenta las cuestiones presentadas arriba, quizá el concepto de "propiedad privada del nosotros" sea la clave para manejar los desafíos genómicos. Este tipo de propiedad podría incluir la responsabilidad social, una propiedad comunitaria, el bien común, o tal vez un tipo de contrato social. Sin embargo, hay preguntas todavía pendientes: ¿cómo definimos lo público?; ¿cómo relacionar lo genético y lo biopolítico?; ¡el "nosotros" se encuentra definido por la parte compartida del genoma humano?

La biopolítica genómica necesita producir un pensamiento utópico que parta de la realidad y le permita afrontar los desafíos de manera optimista. No llegaremos a una biopolítica efectiva si somos incapaces de crear una visión positiva, abrigar horizontes de sentido y esperanza para confeccionar el futuro. Es fácil decir que faltan hechos estables en los que apoyarse a la hora de determinar la biopolítica más adecuada, pero este pretexto potencia la pasividad e impide tomar decisiones. En mi opinión, una de las condiciones ineludibles es la educación básica de la sociedad: no solamente de los científicos, los políticos y los empresarios, sino sobre todo de los consumidores, porque necesitamos

${ }^{44}$ Ferreira Ruiz 2019. 
una utopía informada. Scruton subraya, con razón, que existen usos beneficiosos del pesimismo. Ahora bien, sin cierta cantidad de optimismo la acción no conduce a ningún cambio provechoso. Entonces, ¿̨cuál es la ruta adecuada para utopizar la utopía genómica? ¿La autopropiedad o la sociedad abierta? Las dos ostentan aristas. Es difícil concebir la aceptación de una forma extrema de autopropiedad en el mundo postgenómico, opción que se antoja inviable, según señalan las propuestas de los gobiernos. Siendo esto así, el reto reside en forjar imágenes prospectivas donde el personal genome sea manejado adecuadamente.

Todas las preguntas y dudas comentadas refrendan que proponer una actitud utópica para enfrentar los desafíos de los tiempos contemporáneos es un problema complejo. Con el data sharing que tenemos ahora en las redes sociales y con su creciente popularidad en las aplicaciones genómicas, hemos de aceptar que la base de esta utopía informada será la utopía liberal, aunque sea imperfecta, ligada al modelo contractualista, fundado en el consentimiento informado, la posibilidad de retirar la participación en el modelo y la transparencia del sistema. Aún así, la naturaleza de los datos biológicos es muy distinta a la de los datos personales compartidos en las redes sociales, y ya vimos que compromete a terceras personas de manera peligrosa, tesitura que verifica que el modelo del libre mercado no es una opción a sopesar. Por otro lado, la responsabilidad moral amplia convertida en responsabilidad legal, caso de Kendall, tampoco ayuda. Sin reglas para limitar la responsabilidad genómica individual, sería razonable afirmar que somos responsables por todos los seres vivos. Cuestiones similares se debaten actualmente en relación a la justicia genómica desde múltiples puntos de vista.

Los problemas del mundo genómico son recientes: al imaginar la utopía genómica carece de sentido buscar apoyo en los clásicos de la utopía médica del pasado, como la de Francis Bacon (La Nueva Atlántida, I626), Cyrano de Bergerac (El otro mundo, I657-I662) o John Macmillan Brown (Limanora: the Island of Progress, 1903), pues carecen de contenidos adecuados para afrontar las coyunturas presentes. Una manera de salvar la cuestión de la propiedad y la responsabilidad sería aceptar la noción de propiedad comunitaria en relación a la información genética. ¿Qué significa esta comunidad? Pensemos en comunidades genéticas, por ejemplo en las propuestas microutópicas de AncestryDNA o 23andMe, grupos que comparten información genética capaz de influir significativamente en el mejoramiento de los servicios médicos y el desarrollo de la ciencia. Mi responsabilidad, por lo tanto, se ampliaría a este conjunto de gente, siendo el caso que mi libertad de compartir o no mis datos se delimitaría por los derechos de terceros.

En el nivel geopolítico, la desigualdad tecnológica entre las sociedades pone en riesgo la seguridad nacional y amenaza la visión utópica de la propie- 
dad comunitaria. Si otra comunidad tuviera un nivel tecnológico más avanzado, ¿permitiríamos que accedieran a los datos de la nuestra? La comunidad decidiría. ¿Qué sucedería con aquellos individuos que no aceptan compartir sus datos? A fin de protegerlos, se necesitaría asegurar su acceso a los servicios médicos adecuados. Claro está que, para participar en la comunidad genómica y utilizar las tecnologías de la medicina personalizada, tendrían que ceder una parte de su privacidad. En cuanto al control de este sistema y al consentimiento informado, se necesitaría igual acceso a los datos de la inteligencia colectiva, o incluso el mejoramiento humano extremo, el cual permitiría, supuestamente, incrementar el potencial de nuestro cerebro. Teniendo en cuenta que en otras áreas de la vida ya tenemos bastante confianza en la ayuda de los algoritmos, es muy probable que vaya a pasar lo mismo con los servicios médicos en el mundo postgenómico. Es preciso asegurar que todos tengan acceso a la información adecuada sobre las posibilidades de la medicina personalizada y los riesgos y beneficios de la secuenciación del genoma: no solo aquellos que contribuyan al desarrollo de este conocimiento.

El papel del discurso sigue siendo extremadamente importante para la construcción de visiones optimistas o pesimistas y la modulación de las actitudes públicas y la política. No digo que necesitemos un cambio discursivo drástico que nos lleve a divulgar cuentos de hadas. Mi posición es que el análisis crítico del discurso contribuiría a separar lo ficticio de lo factual y evaluar los textos formativos de la sociedad postgenómica como útiles o inútiles en la creación de una biopolítica utópica del futuro. Probablemente se abra un periodo transitorio durante el cual las dificultades abran el camino al diálogo entre los representantes del pensamiento utópico y distópico, diálogo que permitiría optimizar la información sobre el tema, familiarizar a los individuos con las tecnologías y reducir la tasa de exclusión de la medicina basada en el genoma. Gracias a este periodo, tal vez se desarrollarían medidas utópicas viables, mientras las sociedades se acostumbran a los cambios que la genómica trae consigo.

\section{Conclusiones}

Este artículo empezó presentando las dimensiones utópicas y distópicas de la biopolítica contemporánea referentes a la genómica. La pregunta más importante es la de si es posible evitar las soluciones distópicas y si el discurso utópico desarrollado en algunas pistas de la genómica (la narrativa biotecnológica, la narrativa de la sociedad abierta) es adecuado. Admitiendo que los discursos utópicos tienen sus desventajas, son, no obstante, la única alternativa para combatir el fatalismo del pensamiento distópico. Desde luego, necesitan 
ajustes y regulaciones que los concreticen, sobre todo si reparamos en que la versión utópica neoliberal de la desregulación parece tan peligrosa como la totalitaria.

En 2018 Fajardo defendió que se necesita un marco normativo que regule los servicios genómicos. Añadió también que antes de que la ley entre en vigor normalmente pasan diez ańos. Por este motivo, urge desarrollar el debate público sobre la biopolítica genómica cuanto antes. Incluso Morgan (200I) dice que es imprescindible hacer un esfuerzo al respecto. Crichton, en sus notas en Nexty en su ensayo This Essay Breaks the Law, insiste en que no podemos ignorar los avances científicos y el mercado de las nuevas tecnologías que se están desarrollando aceleradamente. La falta de respuestas adecuadas a los desafíos de nuestra época por parte de las administraciones, la falta de apoyo a los ciudadanos con una educación adecuada y la ausencia de guías y regulaciones del uso de los datos genómicos implican un incumplimiento del papel del gobierno.

He subrayado que necesitamos visiones utópicas con las que construir perspectivas deseables del futuro e intervenir en su creación. En el caso de la biopolítica genómica las necesitamos más si cabe, dado el pesimismo genómico predominante en la cultura, el cual nos transforma en receptores pasivos de las reglas dictadas por otros. La conclusión a la que he llegado es que la educación sobre genómica y las variedades de la biopolítica, más el entrenamiento en el pensamiento crítico optimista y pesimista, son recomendables para lidiar con las problemáticas de la condición postgenómica de manera responsable. Al fin y al cabo, "una buena ciencia y una buena sociedad se hacen juntas". ${ }^{45}$

${ }^{45}$ REARDON 2017, 141. La traducción es mía. 


\section{BIBLIOGRAFÍA}

Atwood, M. 2003, Oryx and Crake, Londres: Bloomsbury.

Aтwоod, M. 2009, The Year of the Flood, Londres: Bloomsbury.

Atwood, M. 2013, MaddAddam, Londres: Bloomsbury.

Bacigalupi, P. 2009, The Windup Girl, San Francisco: Night Shade Books.

Bernstein, R. i 997, “The New Jules Verne, Like '1984’ But Older”, The New York

Times. https://www.nytimes.com/1996/12/27/books/the-new-jules-verne-like-

1984-but-older.html. Fecha de acceso: 03.07.2020.

Canguilhem, G. 1978, On the Normal and the Pathological, Dortrecht: Reidel.

Claeys, G. 2017, Dystopia: A Natural History, Cambridge: Cambridge University Press.

Clayton, J. y Wald, P. 2007, "Editors' Preface: Genomics in Literature, Visual Arts, and Culture", Literature and Medicine, 26 (1): vi-xvi

Contreras, J. L. 2008, “Next and Michael Crichton's Five-Step Program for Biotechnology Law Reform”, Jurimetrics, 48 (3), Disponible en SSRN: https://ssrn. com/abstract $=1486709$.

De la Fuente, J. R. 2004, "Ética y genómica”, Gaceta médica de México, 140 (1). http://www.scielo.org.mx/scielo.php?script=sci_arttext\&pid=S001638132004000100022. Fecha de acceso: 11.07.2020.

Declaración Internacional sobre los Datos Genéticos Humanos 2003, Organización de las Naciones Unidas para la Educación, la Ciencia y la Cultura. http://portal unesco.org/es/ev.php-URL_ID=17720\&URL_DO=DO_TOPIC $\& U R L$ SECTION=201.html. Fecha de acceso: 11.07.2020.

Dewey-Hagborg, H. 20 I7, “The Postgenomic Identity”, Leonardo, 50 (5): 531.

Ditter, Ch. 2020, Biohackers (series), Netflix.

Esposito, R. 20 I I, Bios: Biopolitica y filosofía, Buenos Aires: Amorrortu.

FAJARdo, M. 2018, "El nuevo botín: avance de la genómica abre debate sobre la propiedad de la información genética en Chile", El Mostrador, 14.05.2018. https://www.elmostrador.cl/cultura/2018/05/14/el-nuevo-botin-avance-dela-genomica-abre-debate-sobre-la-propiedad-de-la-informacion-genetica-enchile/. Fecha de acceso: 07.07.2020.

Ferreira Ruiz, M. 2019, "Información biológica: ¿La teoría de la información ataca de nuevo?", Manuscrito, 42 (1). https://www.scielo.br/scielo.php?script=sci_ arttext\&pid=S0100-60452019000100169. Fecha de acceso: 06.07.2020.

Foucault, M. 2008, The Birth of Biopolitics. Nueva York: Palgrave Macmillan.

Goven, J. y Pavone, V. 20 I 5, "The Bioeconomy as Political Project: A Polanyian Analysis", Science, Technology, and Human Values, 40 (3): 302-37.

Graham, P. W. i98 I, "A Mirror for Medicine: Richard Selzer, Michael Crichton, and Walker Percy", Perspectives in Biology and Medicine, 24 (2): 229-39. 
Han, B.-C. 20 I 4, Psicopolitica: Neoliberalismo y nuevas técnicas de poder, A. Berges (trad.), Barcelona: Herder.

Harrison, H. 2008, Make Room! Make Room! Nueva York: Orb Books.

Hyde, M. J. y Herrick, J. A., (ed.) 20I3, After the Genome: A Language of Our Biotechnological Future, Waco, TX: Baylor University Press.

Informe de la ponencia de estudio sobre genómica, Boletín Oficial de las Cortes Generales. Senado. XII Legislatura, Núm. 341. 13.02.2019. http://www.senado. es/legis12/publicaciones/pdf/senado/bocg/BOCG_D_12_341_2574.PDF .

Johnson, S. B., Slade, I., Giubilini, A. y Graham, M. 2020, "Rethinking Ethical Principles of Genomic Medicine Services", European Journal of Human Genetics 28: 147-54. https://www.nature.com/articles/s41431-019-0507-1. Fecha de acceso: 11.07.2020.

Jonas, H. 1985, The Imperative of Responsibility: In Search of an Ethics for the Technological Age, Chicago: University of Chicago Press.

Jones, P. 2008, "Science Comes Second in Next", en Grazier, K. N. (ed.), The Science of Michael Crichton: An Unauthorized Exploration into the Real Science Behind the Fictional Worlds of Michael Crichton, Dallas: BenBella Books, 155-73.

KIng, T. 2006-2010, Heroes (series), NBC.

KInG, S. 20 I I, The Stand, Nueva York: Anchor Books.

Kress, N. 1996, Beggars and Choosers, Nueva York: Tom Doherty Associates.

Kress, N. 1997, Beggars Ride, Nueva York: Tom Doherty Associates.

Kress, N. 2009, Beggars in Spain, Nueva York: Harper Collins.

Latour, B. y Woolgar, S. I985, Laboratory Life: the Construction of Scientific Facts, Princeton, N.J.: Princeton University Press.

Lemke, T. 20 Iо, Biopolitics: An Advanced Introduction: Biopolitics: Medicine, Technoscience, and Health in the Twenty-first Century, Nueva York: New York University Press.

Lemke, T. 20 I3, Perspectives on Genetic Discrimination, Nueva York: Routledge.

Mathaiyan, J., Chandrasekaran, A. y Davis, S. 2013, "Ethics of genomic research", Perspectives in Clinical Research, 4 (1): 100-4.

michaelcrichton.com http://www.michaelcrichton.com/.

Mitchell, D. 20 i 2, Cloud Atlas, Londres: Sceptre.

More, T. i970, Utopia, P. Turner (coord.), Harmondsworth: Penguin Books.

Morgan, D. 200 I, Issues in Medical Law and Ethics, Londres: Cavendish Publishing.

Mukherjee, S. 2017, El gen: Una historia intima, Joaquín Chamorro Mielke (trad.), Barcelona: Debate.

Nelkin, D. y Lindee, M. S. 2004, The DNA Mystique. The Gene as a Cultural Icon, Ann Arbor: University of Michigan Press. 
Niccol, A. I997, Gattaca (película), Columbia Pictures.

Nuffield Council on Bioethics 20 I 8, "Heritable genome editing: action needed to secure responsible way forward", Press Release, https://www.nuffieldbioethics. org/news/heritable-genome-editing-action-needed-secure-responsible. Fecha de acceso: 24.04.2020.

Nussbaum, M. 20 i I, Creating Capabilities: The Human Development Approach, Cambridge, MA: Harvard University Press.

Oreskes, N. 2019, Why Trust Science?, Princeton: Princeton University Press.

Oreskes, N. y Conway, E. M. 20 i I, Merchants of Doubt: How a Handful of Scientists Obscured the Truth on Issues from Tobacco Smoke to Global Warming, Nueva York: Bloomsbury.

Penchaszadeh, V. B. 20i8A, "Desafíos éticos de la big data en salud", en Ruiz DE Chávez, M. H. y PiÑA, R. J. (ed.), Bioética y nuevas fronteras de la genética, Ciudad de México: Fontamara, 85-94.

Penchaszadeh, V. B. 2018в, "Ética de las investigaciones en genética humana”, en M. H. Ruiz de Chávez y Piña, R. J. (ed.), Bioética y nuevas fronteras de la genética, Ciudad de México: Fontamara, 27-42.

Primc, N. 2020, "Do we have a right to an unmanipulated genome? The human genome as the common heritage of mankind", Bioethics 34: 41-8.

ResniK, D. B. 2005, "The human genome: common resource but not common heritage", Frontis 5: 197-210.

Reardon, J. 2017, The Postgenomic Condition. Ethics, Justice and Knowledge After the Genome, Chicago: University of Chicago Press.

Rodríguez Merino, J. M. 20 I 5, Ética y derechos humanos en la era biotecnológica, Madrid: Editorial Dykinson.

Rose, N. 2008, The Politics of Life Itself: Biomedicine, Power, and Subjectivity in the Twenty-First Century, Princeton: Princeton University Press.

Russo, A. y Russo, J. 2019, Avengers: Endgame (película), Walt Disney Studios.

SAndBerg, A. 2013, "Morphological Freedom: Why We Not Just Want It, but Need It", en More, M. y Vita-More, N. (ed.), The Transhumanist Reader. Classical and Contemporary Essays on the Science, Technology, and Philosophy of the Human Future, Chichester: Wiley-Blackwell, 56-64.

Schmeink, L. 2016, Biopunk Dystopias. Genetic Engineering, Society and Science Fiction, Liverpool: Liverpool University Press.

Schwember Augier, F. 20 i9, "Las vicisitudes de la esperanza liberal: de la utopía minarquista a la distopía anarcocapitalista”, Estudios Públicos, 154: 87-124.

Scruton, R. 20io, Usos del pesimismo. El peligro de la falsa esperanza, Gonzalo Torné de la Guardia (trad.), Barcelona: Ariel.

Scotт, R. I982, Blade Runner (película), Warner Bros.

SEN, A. I992, Inequality Reexamined, Cambridge, MA: Harvard University Press. 
Stapleton, P. y Byers, A. (ed.) 2015, Biopolitics and Utopia: An Interdisciplinary Reader, Londres: Palgrave Macmillan.

Tutton, R. 20I I, "Promising pessimism: Reading the futures to be avoided in biotech", Social Studies of Science 41 (3): 411-29.

Van Est, R. y Stemerding, D. (ed.) 2012, Making Perfect Life. European Governance Challenges in 21st Century Bio-engineering, Final Report. STOA. https://www.rathenau.nl/sites/default/files/Making_Perfect_Life_Final_Report_2012.pdf. Fecha de acceso: 24.07.20.

Waldby, C. y Mrtchell, R. 2006, Tissue Economies: Blood, Organs, and Cell Lines in Late Capitalism, Durham: Duke University Press.

Weidenslaufer, C., Torres, R. y Hernández, R. 2019, Medicina Genómica, Biblioteca Nacional de Chile. https://obtienearchivo.bcn.cl/obtienearchivo?i d=repositorio/10221/27426/1/BCN_Medicina_Genomica_2019.pdf. Fecha de acceso: 20.07.20.

Wells, D. 2014, Partials Sequence: the Complete Collection, Nueva York: Balzer + Bray.

Wells, H. G. 1973, The Island of Doctor Moreau, Harmondsworth: Penguin. 
